\title{
Experience in the Development and Delivery of a One Semester Capstone Design Course for Final Year Civil Engineers at the University of Manitoba
}

\author{
M. J. Frye, Ph.D., P.Eng \\ Senior Instructor/Engineer-in-Residence \\ Design Engineering \\ Faculty of Engineering \\ University of Manitoba \\ jfrye@cc.umanitoba.ca
}

\author{
M. G. Britton, Ph.D., P.Eng \\ Professor/Associate Dean (Design Education) \\ NSERC Chair in Design Engineering \\ Faculty of Engineering \\ University of Manitoba \\ ron_britton@umanitoba.ca
}

\begin{abstract}
This paper describes the experience in the organization and delivery of a one-term Capstone design project for students in their final year of the Civil Engineering program at the University of Manitoba. The Capstone design course was first introduced into the Civil Engineering program at the University of Manitoba in the fall semester of 2002. It has now been delivered three times. It is a projectbased course involving teamwork and encompassing knowledge in transportation, water resources, environmental, materials, geotechnical and structural engineering. The main objective of the Capstone project is to facilitate the transition from the academic environment to the "real world" (industry) through the participation in a meaningful design project under the general guidance of an industry mentor. Local consulting engineering companies volunteer to mentor the student teams.
\end{abstract}

Design projects have been provided by the City of Winnipeg who agreed to act as the sponsor/client for the first three years of the Capstone program. Sponsorship involves selecting a suitable design project and preparing a request for a proposal (RFP). Projects provided by the City to date have included: (1) the preliminary design of a pedestrian bridge over the LaSalle River, and (2) the preliminary design of a grade separation at a congested intersection in Winnipeg. Project deliverables include a written response to the RFP, a progress report, and final report. Student teams are also required to give an inclass presentation to the client of their response to the RFP and the progress report. The presentation of the final report is open to the public and is held immediately following the last day of classes.
The quality of the work has improved over the three years. This is attributed not only to the overall organization of the course but also because, so far, each of the student teams has wanted to "do better" than their predecessors. Industry mentors have also become more comfortable with their role and now have more realistic expectations of the capabilities of the students.

Successful completion of the Capstone project is a challenge and depends on teamwork and effective project management. The time commitment is significant, and can impact other courses that the student is taking. Despite the significant workload students who have taken the course have with few exceptions said that they appreciated the opportunity to apply their skills to a real project involving all aspects of civil engineering. A spin-off benefit has been that the students have a first hand opportunity to meet and evaluate perspective employers and industry can evaluate perspective employees.

\section{Introduction}

The Capstone Design Project (CDP) course (023.459) was first introduced into the fourth year Civil Engineering program at the University of Manitoba in the fall term of the 2003/2004 regular session. It is a six credit hour one semester required course. The course has now been offered three times.

The principal objective of the CDP course is to facilitate a smooth transition between the academic world and industry through participation in a meaningful team-based design project under the mentorship of both academic and non-academic professionals. The design project involves all civil engineering design aspects including: transportation, 
water resources, environmental, materials, geotechnical and structural. Where possible, the project also involves students from other faculties. The project provides students with an opportunity to apply and develop their project management, communication, decision-making and collaboration skills. The project also requires the students to prepare cost estimates for their designs.

It was deemed important to have significant industry involvement in all aspects of the design project. The City of Winnipeg, Department of Public Works has acted as the project sponsor (client) for the first three years of the program. Local consulting engineering firms mentor each of the student teams. Professional practitioners also participate as guest lecturers on topics specific to the project.

Involvement and full support of all Civil Engineering academic staff have always been considered to be crucial to the success of the CDP. Throughout the term, academic staff have made themselves available as consultants to the student design teams.

The challenge to the student teams who have participated in the CDP has always been to deliver a quality product within a very short timeframe. The challenge to the course instructor(s), project sponsors and team mentors has been to provide the student teams with the opportunity, environment and support necessary to accomplish this task.

This paper describes the organization and delivery of the CDP for final year Civil Engineering students at the University of Manitoba. It concludes with a summary of the experiences and feedback provided by those who have participated in the course.

\section{Course Structure and Delivery}

Some of the important considerations in establishing the CDP course structure and delivery method were:

1) Project selection,

2) Student team size and composition,

3) Participation by students from other faculties,

4) Industry collaboration,

5) Academic staff collaboration,

6) Project phases and deliverables,

7) Project management and project records,

8) Evaluation, and

9) Course delivery.

\subsection{Project Selection}

The City of Winnipeg Department of Public Works was approached and agreed to sponsor the CDP over the first three years of the Civil Engineering Capstone program. As the project sponsor, the City in essence assumed the role of the client. The City provided a list of projects that they had an interest in pursuing at some future date. Several months in advance of the first offering of the CDP, the list provided was reviewed and a project selected. Criteria for selection were, that as far as possible, the project included all aspects of civil engineering design and that a design team of five to six students in the three-month time frame could complete the project.

The project was initiated by the sponsor providing a request for proposals (RFP) in the same format used for all public works projects undertaken by the City. The City requested that the CDP be treated as a design competition and agreed to award a cash prize for the design judged to best meet their requirements and needs as established by the RFP.

The following projects were selected for the CDP:

Fall Term 2002 (2002/2003 Regular Session) "Preliminary Design of a Pedestrian Bridge over the LaSalle River in St. Norbert Manitoba". The first year of the CDP only one design team of four students registered for the course. The limited registration was attributed to the fact that it was a transition year from the previous individual thesis to the CDP and many students opted still to do an individual thesis. Also many students who were eligible had decided to defer the CDP until the following year. It was decided to proceed with the CDP but to repeat the project the following year.

Fall Term 2003 (2003/2004 Regular Session) Repeat of "Preliminary Design of a Pedestrian Bridge over the LaSalle River in St. Norbert Manitoba". In the second year of CDP, twenty-six students including three students from the Faculty of Architecture registered for the course.

Fall Term 2004 (2004/2005 Regular Session) "Preliminary Design of a Grade Separation at Regent Avenue and Lagimodière Boulevard". A total of twenty-nine students registered for the course.

\subsection{Student Team Size and Composition}

Apart from the first year of the CDP, the size of the teams has been limited to five or six Civil Engineering students. The number of teams therefore 
depends on the total number of students who register for the course.

For the most part, students do not form their own teams. All Civil Engineering students eligible to register for the CDP are surveyed several months prior to the start of the fall term. The students are asked to:

(a) indicate the aspects of the project that they would prefer to work on (structural, geotechnical etc.),

(b) outline their previous work experience,

(c) state their course workload for the CDP term,

(d) state the design courses that they have successfully completed,

(e) indicate two other students registered for the CDP with whom they would prefer to work, and

(f) indicate their willingness to serve as a team project manager.

The responses to the survey are tabulated and are used to assign students to a team. Grade point average is also considered by the instructor when forming the teams.

\subsection{Participation by Students from Other Faculties}

To date, participation by students from other faculties has been limited to students from the Faculty of Architecture. Over the three years that the CDP course has been offered students from the Faculty of Architecture have participated in the course. This participation has taken place at three different levels:

(a) Fall 2002 - Architecture students worked with the design team on Universal Design aspects of the project in a one day workshop.

(b) Fall 2003 - Architecture students registered for the CDP course and were assigned to a design team.

(c) Fall 2004 - Landscape Architecture students participated as sub-consultants to the design teams and received credit as a major assignment within a course offered within their own department.

\subsection{Industry Collaboration}

Strong and effective industry involvement in the CDP has been achieved through a student team mentorship program and through the participation of practitioners from both government and local consultants as guest lecturers and advisors on topics specific to the CDP.

A list of potential industry mentors was prepared based on the recommendation of the project sponsor. The sponsor based their recommendations on their experience with the design consultants on past projects similar to the CDP. Senior people in the organizations were then approached to discuss the $\mathrm{CDP}$ and to commit to the mentorship program. Each student project team was matched with an industry mentor.

Industry mentors are required to provide general direction and advice to their assigned team over the course of the project. To facilitate effective communication between the student teams and their mentors, the teams are required to have a project meeting with their team mentors at least once every two weeks over the term. Team mentors are provided with copies on all project correspondence. Industry mentors are not expected to supervise the project, however, they are expected to review progress, provide feedback and provide advice on issues relevant to the project.

In the early part of the term the practitioners from government and local engineering consulting firms are invited to provide lectures on topics specific to the CDP. They also are asked to make themselves available to meet with the teams on an individual basis to provide feedback and advice.

\subsection{Academic Staff Collaboration}

All staff of the Civil Engineering Department are made aware of the upcoming CDP and are encouraged to provide input. Professors are expected to be available over the term to consult with students on design issues within their area of expertise.

In a number of cases, courses relevant to the CDP are taught concurrently with the CDP or in the following Spring Term. Professors who teach courses that run concurrent with CDP will often tailor their lectures and assignments around design issues that will be encountered by the design teams. Professors who teach a course relevant to the CDP in the following Spring Term provide special lectures covering the course content relevant to the CDP.

All Civil Engineering staff attend the final presentations.

\subsection{Project Phases and Deliverables}

The fall term begins the first week of September and ends the first week of December. The CDP is divided into three phases:

(a) Phase 1 - Response to the RFP (due first week in October),

(b) Phase 2 - Progress Report (due first week in November), and 
(c) Phase 3 - Final Report (due first week in December).

At the end of Phase 1, the student teams are required to present a written response to the RFP and give a thirty minute oral presentation of their response. At the end of Phase 2, the student teams are required to present a written progress report and again give a thirty minute oral presentation of their progress report. At least two design alternatives must be presented in the progress report. The presentations for Phase 1 and 2 of the CDP are open, but are usually only attended by the instructor, the project sponsor and the other teams.

The student teams present their final report in an open public presentation at the end of Phase 3. Each team is allowed forty-five minutes to present their final report. The presentation must also include project posters and may include a physical model.

\subsection{Project Management and Project Records}

For the student teams to meet the established milestones for each of the three phases of the CDP requires a sound work plan and effective project management. It requires all students to commit to both the work plan and the team goals. In terms of individual student workload, students are advised that they are expected to devote from eight to ten hours per week beyond lecture and tutorial time to the CDP.

Overall project management is left to project managers appointed by the teams themselves. The project manager is required to assign duties to the team members and to chair all project meetings including meetings with the team industry mentor. Team project meetings are held once a week. Every second week the team mentor attends the meeting.

At the start of the project, each team is provided with a draft work plan. From the draft work plan, each team develops a team Gantt chart. Each week over the term the Gantt chart must be updated and submitted to the course teaching assistant (TA) for review. A file containing the Gantt charts, project meeting agendas, meeting minutes and project documentation must be maintained and submitted at the end of the project with the final report. In addition, each team member is required to keep a daily journal.

\subsection{Evaluation}

Student marks for the CDP are based on both individual performance and team performance. Fortyfive percent $(45 \%)$ of the individual grade is assigned to individual performance and fifty-five percent $(55 \%)$ is assigned to team performance.
The marks for individual performance result from an assessment of the three oral presentations made by the student at the end of each phase of the CDP, on the peer assessments carried out by the other team members and on an evaluation of individual project journals. The marks assigned to team performance are based on an evaluation of the three oral presentations and written reports presented at the end of each phase of the CDP, project posters and team project records.

Evaluation rubrics were developed and are used to assess both individual and team oral presentations. Oral presentations are evaluated by the course instructor(s) and invited judges. The course instructor(s) and the project sponsor evaluate written reports. The department graphics specialist evaluates the project posters and presentation graphics.

A breakdown of all assigned marks for both individual performance and team performance is provided in Table 1.

Table 1. CDP Evaluation

\begin{tabular}{|l|l|c|}
\hline Individual Performance: & $\begin{array}{l}\text { \% of } \\
\text { Grade }\end{array}$ & Totals: \\
\hline 1. Verbal Communication Skills: & & \\
\hline Phase 1 - Response to RFP & $5 \%$ & \\
\hline Phase 2 - Progress Report & $5 \%$ & \\
\hline Phase 3 - Final Presentation & $10 \%$ & \\
\hline & & $20 \%$ \\
\hline 2. Individual Project Journal & $5 \%$ & $5 \%$ \\
\hline 3. Peer Assessments & & \\
\hline End of Phase 1 & & \\
\hline End of Phase 2 & $5 \%$ & \\
\hline End of Phase 3 & $5 \%$ & \\
\hline & $10 \%$ & $20 \%$ \\
\hline Team Performance: & & $\mathbf{4 5 \%}$ \\
\hline Phase 1 - Written Response to RFP & $5 \%$ & \\
\hline Phase 1 - Team Presentation & $5 \%$ & \\
\hline Phase 2 - Written Progress Report & $5 \%$ & \\
\hline Phase 2 - Team Presentation & $5 \%$ & \\
\hline Phase 3 - Written Final Report & $15 \%$ & \\
\hline Phase 3 - Project Posters & $5 \%$ & \\
\hline Phase 3 - Team Final Presentation & $5 \%$ & \\
\hline Team Project Management Records & $10 \%$ & \\
\hline \multicolumn{1}{|c|}{ TOTAL: } & & $\mathbf{5 5 \%}$ \\
\hline
\end{tabular}

\subsection{Course Delivery}

The CDP is organized and scheduled around the thirteen-week fall term and the three project deliverable milestone dates. The course timetable provides for two one-hour lectures and two three-hour tutorials each week. Lectures are sequenced to parallel the draft work plan and cover material deemed relevant to the project. For example, the first lectures of the term deal with responding to an RFP 
while later lectures might deal with construction cost estimating.

All of the lectures deemed necessary are presented in the first nine weeks of the fall term. This normally requires that a portion of the tutorial time be used for lectures. The remainder of the tutorial time is used for team project meetings and project work. The last four weeks of the term are devoted entirely to team project work.

The CDP course concludes with a presentation symposium day. The first year the CDP course was offered, the final presentation took place immediately following the final examination period. Students, however, overwhelmingly supported scheduling the symposium for the day immediately following the last day of classes for the term. This recommendation has been adopted.

To avoid a delayed or slow startup to the project, it is important that the students begin to develop an understanding of the project and the scope of the work involved, prior to the start of the fall term. Students who will register for the CDP course are now provided with a comprehensive course outline, draft lecture schedule and a copy of the project RFP at least one month prior to the start of the term. Students are also encouraged to make at least one site visit, to begin discussing the project with their classmates, and to become familiar with software that they are likely to use.

\section{Summary of Experience and Feedback}

The three-year experience with the CDP course and the feedback received from students, academic staff and industry participants have shaped and continue to shape the organization and delivery of the course. From the perspective of all those involved with the course, their experiences and feedback can be summarized as follows:

\subsection{Instructor Experience}

- The CDP requires considerable organization. It is important to decide on the project for the coming term as early as possible. Because the workload is significant for the students, it is equally important to let students know what the project is as soon as possible after this decision has been made so that they can begin to prepare.

- A lecture/tutorial schedule is essential. Industry professionals who are invited as guest lecturers need to be contacted as soon as possible to commit to dates.

- It is suggested that a draft work plan for the CDP be prepared. The draft work plan along with the draft of the lecture/tutorial schedule is included in the course outline package that is provided to the students and the industry mentors. With the tight timeframe, this has helped the design teams to get up and running very quickly.

- Deadlines for student reports and presentations are important. They need to be agreed to by the students at the outset of the term and must be adhered to.

- Treating the CDP as a design competition has been successful. The judging of reports and student presentations by course instructors, the CDP sponsors, and industry professionals not involved as industry mentors, has worked well and has been popular with the student teams. It has been observed that at the start of the term a competitive environment has existed and teams have worked independently almost to the point of being secretive. However, towards the latter part of the term a more collegial atmosphere prevailed as teams began to appreciate the efforts of their colleagues.

- Meeting with the team mentors at least a month prior to the start of the term is essential to review the project work plan and expectations. This was found to be particularly important with "first time" team mentors.

- Keeping the project on track is a challenge not only for the students but also for the instructor. Insisting that the project teams meet with their team mentors at least every second week has worked well. It is necessary, however, to insist on agendas and minutes for all team project meetings and that a Gantt chart be maintained and submitted at the end of each week. Frequent meetings with the team project managers using a "coaching approach" as opposed to a "controlling approach" to encourage timely decisions has been successful.

- Students will want to take advantage of the latest technology available to prepare posters, animations and project drawings to be used in their presentations and reports. There is a learning curve for this and significant graphics support from the department graphics specialist(s) is required. The student teams need to meet with the graphics specialist early in the term and on a regular basis throughout the term or they will quickly run into time difficulties with this aspect of the project. 


\subsection{Student Experience and Feedback}

- Many students have commented on the amount of time that they spent on the CDP and it is not surprising that it has established a "reputation" among students as a lot of work. Without exception, however, students appreciate the course and the opportunities that it offers causing many of them to remark that it is; "An awesome course."

- Expect teams to encounter some of the same difficulties encountered in the real world such as breakup of relationships, illness etc. Teams involved in the CDP have encountered these difficulties but have dealt with them.

- Interest in the CDP remains high among graduates. Students who took Capstone in the Fall term of 2003 and are now working in industry, returned the following year to attend CDP presentations. A number of graduates have indicated that they would like to remain involved in the CDP from the industry side.

- Students have commented that through the CDP they have made many valuable industry contacts and that the CDP course is often a topic for discussion at job interviews. "At my job interview most of the questions were about Capstone."

\subsection{Academic Staff Experience and Feedback}

- The academic staff of Civil Engineering has been very supportive of the CDP. Some have expressed the opinion that it should be the "flagship" course for Civil Engineering at the University of Manitoba.

- Professors have made themselves available to advise students on issues that arise from the CDP and where possible have tailored some class lectures and assignments around these issues.

- Some departmental staff have expressed concern that courses they teach have suffered because of the amount of time students spend on Capstone. This has been a problem when CDP presentations have fallen on or close to term tests and/or dates for final examinations. Early attention to scheduling has alleviated this problem. In particular, scheduling the final presentation of the CDP immediately following the last day of classes and making sure there are no exams scheduled for at least two days after, has helped to address staff concerns.

- Industry contacts made through the CDP have also proven to be valuable to new staff members. A number of industry participants have been invited to provide guest lectures in other courses.

\subsection{Industry Experience and Feedback}

- The industry mentor program has proven to be very successful and is at the core of the CDP. The outreach value to the department is significant. The experience has been that the team mentors are senior people with engineering consultant firms who are more than willing to involve all of their staff in the CDP. Despite the time commitment, all team mentors have indicated the desire to participate again the next year.

- Industry professionals are very willing to come to the university to give guest lectures on specific CDP related topics. They just need to be asked. They are also more than willing to meet with individual teams or individual team members to discuss project specific issues.

- Industry participants have remarked that they have been impressed by the quality of the work done by the students and are using the CDP in part to evaluate students for employment. Involvement in the CDP has caused a number of industry participants to make the comment, "I wish we had a course like that when I was in Engineering."

\section{Conclusions}

The one term Capstone Design Project for final year Civil Engineering students at the University of Manitoba continues to evolve and improve. Early indications are that the principal objective of the CDP course of facilitating a smooth transition from the academic world of the student to their careers in industry through participation in a meaningful teambased design project has been achieved. 